\title{
Development and validation of an instrument to measure informational needs of breast cancer patients in Sri Lanka
}

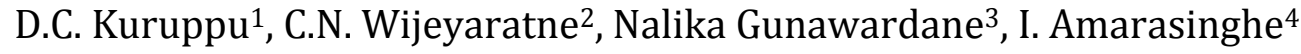 \\ ${ }^{1}$ Medical Library, Faculty of Medicine, University of Colombo, Sri Lanka. \\ 2Professor in Reproductive Medicine, Department of Obstetrics \& Gynecology, Faculty of Medicine, \\ University of Colombo, Sri Lanka. \\ ${ }^{3}$ National Professional Officer (Health Systems Evidence and Analysis), World Health Organisation \\ Country Office, Sri Lanka. \\ 4Former Senior Oncological Surgeon, National Cancer Institute, Maharagama, Sri Lanka.
}

\begin{tabular}{|c|c|}
\hline ARTICLE INFO & Abstract \\
\hline $\begin{array}{l}\text { Article history: } \\
\text { Submission } 15.03 .2017 \\
\text { Acceptance } 15.06 .2017 \\
\text { Available online }\end{array}$ & $\begin{array}{l}\text { Background: Breast cancer is the second most common cancer in the world } \\
\text { and the commonest in Sri Lanka. The provision of relevant and accurate } \\
\text { information in a social-culturally appropriate manner will lead to proper } \\
\text { understanding of the disease and treatment options. }\end{array}$ \\
\hline DOI: & $\begin{array}{l}\text { Objectives: The aim of this study was to develop and validate the Sri } \\
\text { Lankans' Informational Needs Assessment Questionnaire of Breast Cancer } \\
\text { (SINAQ-BC). }\end{array}$ \\
\hline http://doi.org/10.4038/cjms.v54i1.4821 & $\begin{array}{l}\text { Methods: Item generation was through review of literature and using } \\
\text { qualitative research techniques among stakeholders. Thus developed and } \\
\text { pretested } 69 \text { items SINAQ-BC was administered through interviews to } 150\end{array}$ \\
\hline Keywords: & women at least 18 years of age who have been diagnosed as having breast \\
\hline Informational needs & $\begin{array}{l}\text { Analysis (EFA) was used for further item reduction. Internal consistency } \\
\text { reliability and acceptability were also assessed. }\end{array}$ \\
\hline Construct validity & $\begin{array}{l}\text { Results: Exploratory factor analysis determined that } 58 \text { items should be } \\
\text { retained in the questionnaire and that they be best organized into five }\end{array}$ \\
\hline Reliability & $\begin{array}{l}\text { subscales labelled as disease, diagnosis, treatment, physical care and } \\
\text { psychosocial care. SINAQ-BC showed good internal consistency reliabilities } \\
\text { with Cronbach's alpha of } 0.76 \text { to } 0.93 \text {.An average } 30 \text { minutes ( }+5 \text { mins) was } \\
\text { taken to complete the SINAQ-BC and it did not require any additional } \\
\text { explanations demonstrating its acceptability. }\end{array}$ \\
\hline & $\begin{array}{l}\text { Conclusion: The SINAQ-BC demonstrated to be a valid and reliable tool to } \\
\text { assess informational needs of breast cancer patients. It is recommended to be } \\
\text { used to determine informational needs of women with breast cancer and as a } \\
\text { tool to assess effectiveness of educational interventions. }\end{array}$ \\
\hline
\end{tabular}

\section{Introduction}

Breast cancer (BC) is the second most common cancer in the world and the commonest cancer among women. An estimated 1.67 million new cancer cases were diagnosed in 2012. Incidence rates vary nearly four-fold across the world regions,

\section{Corresponding Author:}

D.C. Kuruppu, Medical Faculty, Faculty of Medicine,

Kynsey Road, Colombo 08.

kuruppudc@gmail.com

iD http://orcid.org/0000-0003-0763-0497 with rates ranging from 27 per 100,000 in Middle Africa and Eastern Asia to 92 in Northern America [1]. In Sri Lanka, breast cancer is the commonest cancer among women. The age standardized incidence rate (ASR) of BC in Sri Lanka was 23.0 per 100,000 population in 2010. The crude incidence rate $(\mathrm{CR})$ of the $\mathrm{BC}$ has increased by approximately 1 per 100,000 population from the levels in 2009. One in every 40 females in Sri Lanka has a risk of developing $\mathrm{BC}$ during their lifetime (074 years) [2]. 
Upon diagnosis and during the life thereafter, BC causes a significant emotional impact upon the lives of patients as well as family and friends, work colleagues and the greater community. Many studies reveal that information plays an extremely important role in patients' ability in coping with the disease and their quality of life. Fredette in 1995 [3] stated that information on $\mathrm{BC}$ requires the afflicted woman to be well informed to understand her diagnosis, to develop a positive attitude towards the life amidst the threatening implications of the cancer, and to cope well with the condition. Provision of relevant and accurate information in a social-culturally appropriate manner will lead to proper understanding of their treatment options and outlook they need to adopt towards a healthy future [4]. It is therefore important to assess the information needs of women with BC since such an assessment has not been done in Sri Lanka.

Measuring of informational needs require a tool which should be culturally appropriate. A tool to measure informational needs of $\mathrm{BC}$, named as Toronto Informational Needs Questionnaire (TINAQ), has been developed in the European region [5] but none have been developed for Asian Region. Therefore, development of an appropriate instrument to assess informational needs of $\mathrm{BC}$ survivors to be used in the Sri Lankan context was considered of paramount importance. It is imperative that validity of the survey instrument to measure informational needs of BC patients be also determined. This study aimed to develop a questionnaire to measure the informational needs of a $\mathrm{BC}$ patient and to determine its validity and reliability to assess the needs of information related to diagnosis, treatment modalities and follow up care.

\section{Methods}

\section{Development of the tool}

The development of the tool in the form of an interviewer administered questionnaire followed a step wise process.

First step was generation of items. Items were identified through review of literature and through focus group discussions. Focus group discussions were carried out with $\mathrm{BC}$ survivors, the lay people and the oncologist counselor attached to counselling unit in the National Cancer Institute, Maharagama, and other staff, to find out suitability of selected items and identify the new items. Sixty nine items were generated from a number of sources including findings in the literature and opinion from the multidisciplinary panel comprising experts as well as stakeholders i.e. oncologists, community physicians, radiologists, physiotherapists, nutritionist, medical counsellors, social counsellors, nurses and cancer patients.

In the second step, a consultative meeting was organized at which the same panel grouped the items into different subscales or domains that have been identified from literature survey [5]. Using collective professional experience, items that were thought to be repetitions and culturally inappropriate were removed by consensus. Items were then grouped into eight such subscales or domains of informational needs namely, diseases, diagnosis, investigative tests, treatments, physical care, psychological, care family and finance.

The third step was to convert the items into questions and to develop a draft interviewer administered questionnaire to assess breast cancer patients' information needs. The researchers initially drafted the questionnaire in English. The questionnaire was designed to assess the information needs by inquiring the subjects to rate the importance of each item on a five point scale of 1 (not important), 2 (slightly important), 3 (moderately important), 4 (very important) and 5 (extremely important).

\section{Translation of the tool}

Two translators, both with a high level of proficiency in English and Sinhala, independently translated the questionnaire into Sinhala. The two Sinhala translated versions were then reviewed by an independent expert proficient in both English and Sinhala languages. The items which were agreed upon were accepted for forward translation. Another two bilingual translators, both with a high level of proficiency in English and Sinhala, independently translated the provisional forward translation back into English without referring to the original English version. The two English translated versions were then reviewed by an independent expert, proficient in both English and Sinhala languages. Same way was used to translate the questionnaire into Tamil using two translators both with high level of proficiency in English and Tamil. 
Then questionnaire thus developed was named as Sri Lankans' Information Needs Assessment Questionnaire of Breast Cancer (SINAQ-BC).

\section{Pretesting of the SINAQ-BC}

Pretesting the SINAQ-BC was done among ten BC patients at the Cancer Unit of Teaching Hospital in Galle, to assess the understanding and the clarity in the wording of questions. Administration of each questionnaire was followed by a structured interview conducted by the PI. Based on the interviews, a few modifications were done to the instructions stated for some items.

\section{Validation of the SINAQ-BC}

The SINAQ-BC together with its instructions was shown to a panel of experts, not involved in developing the study instrument, to assess the content validity. The experts agreed that the content assessed by the SINAQ-BC would be a good reflection to improve patients' knowledge on their disease and services provided for them. The experts also decided that content was subjectively appeared on the SINAQ-BC, confirming its content validity and face validity.

In appraising construct validity, Exploratory Factor Analysis (EFA) using principal component analysis (PCA) was used to assess whether SINAQ-BC had any redundant items and also to assess the suitability of its seven subscales structural. Internal consistency reliability of the SINAQ-BC was assessed using Cronbach's alpha. Bartletts test of sphericity and Kaiser-Meyer - Olkin measure was performed to assess sampling adequacy.

\section{Study Population}

The study population was women at least 18 years of age who have been diagnosed as having BC within the period of one year prior to the study.

\section{Sample Size and sampling technique of the validation study}

Nunnally [6] opines that an initial sample of at least 100 subjects is necessary to provide sufficient data for item analysis of a tool being validated. The researcher further says that domain's (subscales) internal consistency, reliability estimates can be made with five subjects per item. The largest subscale in the SINAQ-BC has 19 items with a minimum sample required being 95 (1:5).
Considering these references, 150 subjects were required since this instrument has 69 total items.

Patient visiting outpatient clinics and / or admitted at National Cancer Institute, Maharagama were invited to participate in the study. The patients were not approached on the first day of any new treatment for ethical reasons. Written informed consent was obtained from each patient. A total of $170 \mathrm{BC}$ patients were invited and 156 consented. Interviews were conducted at the convenience of the patient.

\section{Data Collection}

The SINAQ-BC developed above was administered by the PIafter the interview.

\section{Data Analysis}

Exploratory Factor Analysis (EFA) is essential to determine underlying constructs for a set of measured variables. Exploration for redundant items in the SINAQ-BC was based on the results of the exploratory Factor analysis. Following two criteria were used to determine whether an item would be retained.

1. Items with average inter-item correlation of less than 0.20 as the low correlation indicate the item may not be related to topic of interest.

2. When two items had inter-item correlations of 0.80 or higher, indicate that the two items measured the same informational need.

Using the results of EFA, the subscale structure of the SINAQ-BC was also reviewed. Inter correlations of the subscales to total scale and the intercorrelations of the subscales were examined to confirm the suitability of the subscales that were decided upon. Internal consistency reliability for the SINAQ-BC and its subscales was assessed using Chronbach's alpha.

Acceptability was assessed using the average time taken to complete the interview and the response rates. All analysis was carried out using a statistical package for Social Science Version 21.0 (SPSS 21.0) by PI.

The project was approved by the Ethics Committee in the Faculty of Medicine, University of Colombo, Sri Lanka [EC-10-035].

\section{Results}

Validation of Sri Lankans' Informational Needs Assessment Questionnaire of Breast Cancer (SINAQ-BC) 
The response rate was $96.2 \%$. Age range of the study units were $27-70$ years with mean age of 56.28 years $(\mathrm{SD}= \pm 12.87 ; 95 \% \mathrm{CI}=54.20-58.36)$. The majority were married $(70 \%)$ had completed either GCE (O/L) or GCE (A/L) $(64 \%, n=96)$ and $9 \%(\mathrm{n}=9)$ possessed a degree or higher qualification. Approximately half $(49 \%, n=74)$ reported an average household income of Rs. 20,000 - Rs. 30,000. Only $34 \%$ had only undergone surgery as the treatment modality for breast cancer. Thirty three percent had undergone chemotherapy and surgery while balance $33 \%$ had undergone radiation therapy and surgery.

\section{Exploratory Factor Analysis}

Exploratory Factor Analysis performed by principal component analysis using data. Sampling adequacy was confirmed by Barlett's test of Sphericity which was significant at $\mathrm{p}<0.01$ (chi square $=1735.4, \mathrm{df}=$ $105, p=0.000$ and Kaiser-Meyer-Olkin measure of sampling adequacy which was 0.697 , being well above the accepted level of 0.6 ).
Nine items were deleted because their average interitem correlations were below 0.20 .

Finally the SINAQ-BC contained 58 items. All 58 items had item-total correlations of 0.25 or higher, levels considered acceptable by Nunnally [6]. In all retained items, the means fell above the midpoint of the Likert scale (1-5) with standard deviations in the range of $0.4-1.7$.

Analyzed 58 items in SINAQ-BC, indicated five subscales. The Eigen values ranged from $1.020-$ 5.074. The total variance explained was $68.1 \%$. In the Exploratory Factor Analysis, five subscales were formed out of the seven original subscales in the SINAQ-BC where the two subscales diagnosis and investigative tests were combined as diagnosis and the two subscales on family and finances were combined into a subscale of psychological care. Thus, titles of the subscales after combining, the number of items of each subscale with the relevant factor loadings are shown in Table 1.

\section{Table 1: SINAQ-BC by its subscales with the retained items and the factor loadings}

\begin{tabular}{|c|c|c|c|}
\hline \multirow{6}{*}{$\begin{array}{l}\text { Title of the } \\
\text { subscale of } \\
\text { information } \\
\text { needs }\end{array}$} & \multirow[t]{6}{*}{$\begin{array}{l}\text { No. of } \\
\text { items }\end{array}$} & items & Factor Loading \\
\hline & & The changes that can be seen on breast & .794 \\
\hline & & $\begin{array}{l}\text { Detail of the places where they offer breast screening services } \\
\text { (whether they are free of charge, such services in my residence, is } \\
\text { a referral or an appointment needed) }\end{array}$ & .758 \\
\hline & & What one should do, if a breast abnormality is detected & .758 \\
\hline & & Who are at high risk of getting breast cancer & .725 \\
\hline & & What causes breast cancer & .716 \\
\hline \multirow[t]{8}{*}{ Disease } & \multirow[t]{8}{*}{14} & The age at which the women should get screened for cancer & .669 \\
\hline & & How to detect whether I have any other cancer & .663 \\
\hline & & Ways of detecting the cancer early & .629 \\
\hline & & $\begin{array}{l}\text { About breast lumps- why they occur, where they occur, how to } \\
\text { recognize }\end{array}$ & .580 \\
\hline & & Whether all women with risk get the cancer & .563 \\
\hline & & Information about mammography screening & .538 \\
\hline & & Common breast pathologies & .482 \\
\hline & & What can women do to minimize their risk of getting breast cancer & .453 \\
\hline
\end{tabular}


Detail of the places where they offer mammography services

(whether they are free of charge, such services in my residence, is .393

a referral or an appointment needed)

\begin{tabular}{lll}
\hline \multicolumn{2}{l}{} & .648 \\
\hline Why each of the confirmatory tests are necessary & .634 \\
\hline How to prepare for such test & .590 \\
\hline Whether there are different stages of breast cancer and what do & .551 \\
they mean & .545 \\
\hline Whether the tests can identify the stage of it & .544 \\
\hline How women will act in response of either positive or negative & .491 \\
result in each of the above tests. & .480 \\
\hline The investigations that confirm the diagnosis of breast cancer & .463 \\
\hline The reasons why doctors suggest certain additional tests. Eg; X - & \\
rays, bone scans etc. & \\
\hline How my illness could affects my life in the future & \\
\hline what should a breast cancer victim discuss with family / friends & \\
\hline about the illness, if diagnosed
\end{tabular}

\begin{tabular}{lc}
\hline What side effect I should report to the doctor / nurse & .891 \\
\hline If I have side effects how to deal with them & .887 \\
\hline If there are ways to prevent side effects / ease treatment. & .828 \\
\hline The possible side effects of treatment & .824 \\
\hline The need to be in the hospital for treatment / if so, how long & .805 \\
\hline How long will I require treatment & .743 \\
\hline Whether the treatment may give up any time duration. & .703 \\
\hline About treatment for breast cancer & .695 \\
\hline Mode of treatment is given & .657 \\
\hline Whether treatment should do continuously & .647 \\
\hline How to decide particular treatment plan & .621 \\
\hline Any food restriction /important food, during treatment & .612 \\
\hline Any restriction to take other drug (if any), during treatment & .603 \\
\hline
\end{tabular}

Detail of the places where they offer treatment (whether they are free of charge, such services in my residence, is a referral or an .543 appointment needed)

Importance of mental preparation for treatment $\quad .505$

-

When should the breast be examined after surgery .822

How to care for my wound or incision $\quad .786$

$\begin{array}{llll}\text { Physical care } & 5 & \text { When should I commence my usual physical activities } & .784\end{array}$

Any additional therapies required to improve recovery after surgery. 


\begin{tabular}{|c|c|c|c|}
\hline & & \multirow{2}{*}{ How long will it take to heal } & \multirow[b]{2}{*}{.716} \\
\hline & & & \\
\hline \multirow{15}{*}{$\begin{array}{l}\text { Psychosocial } \\
\text { care }\end{array}$} & \multirow{15}{*}{15} & How to tell if the cancer has come back. & .791 \\
\hline & & How to manage mental stresses successfully & .783 \\
\hline & & What are the symptoms to get admitted, after treatment? & .772 \\
\hline & & How to face the society successfully & .759 \\
\hline & & $\begin{array}{l}\text { To be aware other family members about their risk for breast } \\
\text { cancer }\end{array}$ & .735 \\
\hline & & What are the symptoms to come to the clinic immediately? & .711 \\
\hline & & $\begin{array}{l}\text { Detail of the places where they offer counselling services (whether } \\
\text { they are free of charge, such services in my residence, is a referral } \\
\text { or an appointment needed) }\end{array}$ & .719 \\
\hline & & Detail of the places where we are able to buy brassieres $\&$ the cost & .698 \\
\hline & & $\begin{array}{l}\text { Telephone numbers for public (hotline) which can be used to get } \\
\text { information on Breast Cancer }\end{array}$ & .638 \\
\hline & & How often should be followed up in respect to treatment mode? & .631 \\
\hline & & $\begin{array}{l}\text { How should family members discuss about the disease with the } \\
\text { patient at an initial level of diagnosis }\end{array}$ & .533 \\
\hline & & Information on financial support & .467 \\
\hline & & Where my family can go if they need help to deal with my illness & .451 \\
\hline & & Importance of continue treatment \& care & .441 \\
\hline & & Behaviour of newly diagnosed women & .422 \\
\hline
\end{tabular}

As shown in the Table 1 all the retained items contained a factor loading of 0.393 or more.

Table 2 shows that the inter correlations of the subscale to total scale ranged from $0.77-0.89$ and the inter-correlations of the SINAQ-BC subscale scores ranged from $0.47-0.84$. This confirmed that each subscales best correlated with the total tool compared to its correlation to other subscales.

Table 2: Inter-correlation of SINAQ-BC total and subscale scores $(n=150)$

\begin{tabular}{lcccccc}
\hline Subscale & Total & Disease & Investigation & Treatment & $\begin{array}{l}\text { Physical } \\
\text { care }\end{array}$ & $\begin{array}{l}\text { Psychosocial } \\
\text { care }\end{array}$ \\
\hline Disease & .85 & - & & & \\
\hline Investigation & .88 & .74 & - & & \\
\hline Treatment & .89 & .84 & .77 & .50 & - \\
\hline Physical care & .77 & .47 & .55 & .60 & - \\
\hline Psychosocial care & .89 & .58 & .71 & .64 &
\end{tabular}


Internal consistency reliability

Results of internal consistency reliability of the SINAQ-BC are shown in Table 3. Cronbach's alpha for the total and each of the five subscales indicated values $0.76-0.95$ indicating the high reliability.

Table 3: Internal consistency reliability of the SINAQ-BC

\begin{tabular}{ll}
\hline & Cronbach's Alpha \\
\hline Total scale & 0.95 \\
\hline Subscales & \\
\hline Disease & 0.93 \\
\hline Diagnosis & 0.78 \\
\hline Treatment & 0.86 \\
\hline Physical & 0.76 \\
\hline Psychosocial & 0.85 \\
\hline
\end{tabular}

\section{Acceptability of SINAQ-BC}

None of the women had difficulty in responding to the SINAQ-BC and the meantime taken to complete the interview was 30 minutes $( \pm 5$ mins $)$ and all were able to respond to the items without additional explanations.

\section{Discussion}

The SINAQ-BC is the only validated instrument developed to assess informational needs of $\mathrm{BC}$ patients in Sri Lankan context. It is expected to function as a valid measure to identify information needs which facilitate designing of the patient educational programmes.

The existing literature is not rich enough to provide a sound conceptual foundation for informational needs of BC patients. As Flick(1998) and Neuman (1997) have suggested that focus group is useful in exploratory research or in generating new ideas to develop hypotheses $[7,8]$. Hence, the present study used both these methods to generate items of the SINAQ-BC.

A hospital-based cross sectional study design was employed to assess the validity and reliability of the SINAQ-BC. Thus, purposive sampling technique was considered as the best technique to ensure representation of women with an initial diagnosis of breast cancer in the treatment phases of surgery, chemotherapy, radiation therapy.
To be considered as acceptable items in the questionnaire, item analysis was completed as done by Nunnally [6]. Items with item-total correlations of 0.25 or higher levels was considered as an acceptable item in the questionnaire, correlation below 0.20 considered as not interesting items and if two items have inter-item correlation of 0.80 or higher, it considered as same informational need, hence, retained only one item. Rarely both items were retained if they seem to be dealing with different informational needs. Content validity of the instrument was established as emphasized by Latwin in 1994 to assess the content completeness of the instrument [9].

Nunnally [6] opines that an initial sample of at least 100 subjects is necessary to provide sufficient data for item analysis to decide whether the research should be continued or abandoned. The researcher further says that domain's (subscales) internal consistency, reliability estimates can be made with five subjects per item. Accordingly, the largest subscale in the SINAQ-BC has 19 items, a minimum sample would be 95 (1:5). Ferguson \& Cox [10] stated at their pre-analysis that minimum participants to variable ratio would be in between 2:1 - 6:1. Considering these references, 150 subjects were used for the study since this instrument has 69 total items.

Factor analysis is a complex statistical procedure, which essentially reduces a large set of variables into much smaller set of variables with common characteristics [11]. As such, it is an empirical 
method of determining 'the underlying dimensionality' of a set of variables [12]. Factor analysis suggested by Galloway et al. (1997) [5] for the Toronto informational Needs QuestionnaireBreast Cancer (TINQ-BC) was used in the present research.

Reliability refers to the dependability and repeatability of an instrument. Wilkin et. al. [13] explained that if an instrument is more reliable, there is lower element of random error. Reliability also provides an estimate of homogeneity. Cronbach's $\alpha$ is used to estimate the internal consistency reliability of SINAQ-BC. The alpha coefficient for each of the subscales and the total scale was above 0.80 , which is considered as a satisfactory estimate of reliability by Burns \& Grove [14]. Nunnally also said that this is the level necessary for instruments used in basic research [6]. A tool (TINQ-BC) developed by Galloway et.al in 1997 [5] also showed that overall alpha coefficient was 0.97 while the corresponding figure for SINAQ-BC was 0.95. Domain $\alpha$ of TINQ-BC ranged from 0.73 to 0.93 while for SINAQ-BC it was 0.76 to 0.93 .

\section{Conclusion}

The SINAQ-BC demonstrated to be a valid and reliable tool to assess informational needs of $\mathrm{BC}$ patients in relation to diagnosis, treatment modalities and follow up care. This is evident by high internal consistency, reliability, content validity and construct validity. Its validity to assess informational needs was confirmed irrespective of the treatment modality that the patient was undergone. It is recommended that the SINAQ-BC be used to determine informational needs of women with BC in Sri Lanka and as a tool to assess educational interventions to improve knowledge and coping of $\mathrm{BC}$ among patients.

\section{Acknowledgements}

Acknowledge University of Colombo for funding of the study [Research grant AP/3/2012/PG/05]. The authors are thankful to the Director of National Cancer Institute, Maharagama, Director of Teaching Hospital in Galle and all health professionals in these two hospitals for the immense support rendered.

\section{References}

1. Estimated cancer incidence, Mortality and Prevelance Worldwide in 2012. GLOBOCAN 2012: http://globocan.iarc.fr/Pages/fact_sheets_canc er.aspx (accessed 28 Feb 2017).

2. Cancer incidence data: Sri Lanka 2010. $12^{\text {th }}$ Publication. Colombo: National Cancer Control programme, 2016.

3. Fredette, S.L. Breast cancer survivors: concerns and coping. Cancer Nurse. 1995; 18: 35-46.

4. Johnson JD, Meischke H. Women's preferences for cancer information from specific communication channels. American Behavioural scientist. 1991; 34: 742-755.

5. Galloway S., Graydon J., Harrison D., et.al. Informational needs of women with a recent diagnosis of breast cancer: development and initial testing of a tool. Journal of Advanced Nursing. 1997; 25:1175-1183.

6. Nunnally J.C. Psychometric Theory; $2^{\text {nd }}$ edition,McGraw-Hill Book Company, Toronto, 1978: 278-282.

7. Flick, U. An introduction to qualitative research. Sage: London, 1998.

8. Neuman, W.L. Social research methods qualitative and quantitative approaches, $3^{\text {rd }}$ ed., Allyn and Bacon, Boston, MA, 1997.

9. Litwin MS. Measuring health related quality of life in men with prostate cancer. Journal of Urology. 1994;152:1882-1887.

10. Ferguson, E. and Cox, T. Exploratory Factor Analysis: A Users'Guide. International Journal of Selection and Assessment, 1993; 1: 84-94. doi:10.1111/j.1468-2389.1993.tb00092.x

11. Templeton H.R.M. \& Coates V.E. Adaptation of an instrument to measure the informational needs of men with prostate cancer. Journal of Advanced Nursing, 2001; 35(3), 357-364.

12. Polit D.F. Data Analysis and Statistics for Nursing Research, Prentice Hall, London, 1996.

13. Wilkin D., Hallam L. \& Doggett A.M. Measures of Need and outcome for Primary Health Care, Oxford University Press, Oxford.1992. 
14. Burns N. \& Grove S.K. Understanding Nursing Research, W.B. Saunders Co. : London, 1995. 